\title{
STUDI KOMPARATIF PENDAPATAN, BIAYA DAN KELAYAKAN USAHA AGROINDUSTRI GULA SEMUT PADA SETIAP PELAKU RANTAI PEMASARAN
}

\author{
Dindy Darmawati Putri ${ }^{1}$ * \\ ${ }^{1}$ Program Studi Agribisnis, Jurusan Sosial Ekonomi Pertanian, \\ Fakultas Pertanian Universitas Jenderal Soedirman, Purwokerto \\ Jl. Dr. Soeparno, Karangwangkal, Purwokerto 53122 \\ *Corresponding author: dindy.putri@unsoed.ac.id
}

\begin{abstract}
This study aims to determine the comparative analysis of income, costs, and feasibility analysis of agro-industry in brown sugar agro-industry marketing chain in the Special Region of Yogyakarta. The research method used a descriptive analysis method. This research was conducted in Girimulyo and Kokap Districts as brown sugar production centers. The method of data collection is done by survey technique. The method of sampling is simple random sampling consisting of brown sugar crafters, collectors, and Central Processing Unit (CPU) of 60 samples. The results showed that the highest profit was in the Central Processing Unit (CPU), then the collectors, and finally at the level of household-scale brown sugar crafters. This is due to the different business scales, limited capital, and raw materials which become the obstacles of the craftsmen in developing their businesses. While seen from the feasibility of the $R C$ ratio, all $R C$ ratios $>1$ means that all businesses in the marketing chain are feasible.
\end{abstract}

Keywords: comparative, brown Sugar, coconut, agro-industry, $R C$ ratio

\begin{abstract}
Abstrak: Penelitian ini bertujuan untuk mengetahui pendapatan, biaya, dan kelayakan usaha agroindustri pada setiap pelaku rantai pemasaran agroindustri gula semut di Daerah Istimewa Yogyakarta. Metode penelitian menggunakan metode deskriptif analisis. Penelitian ini dilakukan di Kecamatan Girimulyo dan Kecamatan Kokap sebagai sentra produksi gula semut. Metode pengumpulan data dilakukan dengan teknik Survey. Metode pengambilan sampel secara simple random sampling yang terdiri dari petani/perajin gula semut, Pengepul dan Central Processing Unit (CPU) sebanyak 60 sampel. Hasil penelitian menunjukkan bahwa keuntungan tertinggi ada pada Central Processing unit (CPU), kemudian pedagang pengepul, dan terakhir adalah di tingkat perajin gula semut skala rumah tangga. Hal tersebut disebabkan skala usaha yang berbeda, keterbatasan modal dan bahan baku menjadi hambatan perajin dalam mengembangkan usahanya. Sedangkan dilihat dari kelayakan RC ratio semua $\mathrm{RC}$ ratio $>1$ artinya pada semua usaha pada rantai pemasaran layak untuk dijalankan.
\end{abstract}

Kata Kunci: komparatif, gula semut, kelapa, agroindustri, RC rasio

\section{PENDAHULUAN}

Iryanti (2011) mengatakan bahwa agroindustri adalah salah satu cabang industri yang mempunyai hubungan antara industri hulu dan industri hilir yang erat dan langsung dengan pertanian. Pengembangan agroindustri berbasis sumberdaya lokal merupakan salah satu program pemerintah untuk mendukung peningkatan kualitas ekspor Indonesia, dari produk komoditas ke produk yang mempunyai sertifikasi dan branding. Pengembangan agroindustri terutama ditujukan untuk meningkatkan nilai tambah komoditas pertanian, memperluas lapangan pekerjaan meningkatkan volume ekspor dan mendorong pertumbuhan ekonomi pedesaan. Pemanfaatan bahan baku pangan lokal dalam agroindustri 
diharapkan dapat meningkatkan keberagaman dan ketersediaan produk pangan. Sejalan dengan hal tersebut Wibowo et al (2020) menjelaskan kemajuan teknologi agroindustri akan mampu mendorong ke arah diversifikasi produk untuk memenuhi kebutuhan manusia maupun pengguna lainnya atau meningkatkan pangsa pasar hasil olahan gula kelapa.

Kelapa merupakan komoditas yang banyak ditemukan di Indonesia. Menurut Antriyandarti (2019), agar dapat menjual kelapa dengan harga yang lebih tinggi, petani kelapa mengolahnya menjadi produk bernilai tambah tinggi (VCO, minyak kelapa, gula kristal, sabun mandi dan produk kosmetik lainnya), dan memasarkan produk kelapa ke seluruh nusantara bahkan mengekspon ke pasar internasional. Pengembangan agroindustri kelapa telah berkembang pesat dengan adanya ekspor komoditas olahan kelapa yaitu gula kelapa kristal atau dikenal dengan gula semut. Perkembangan pasar komoditas gula kelapa tersebut mengangkat industri-industri kecil rumah tangga sebagai produsen gula kelapa. Harga gula semut yang tinggi berpengaruh terhadap gula kelapa yang selama ini sangat rendah menjadi tinggi.

Peneliti sebelumnya Nugraheni (2014), Purwiyati (2015), dan Wijayanti (2016) telah melakukan penelitian gula semut di Kabupaten Kulon Progo dan sekitarnya. Namun penelitian hanya mengkaji efisiensi dan kinerja agroindustri secara keseluruhan. Hasil penelitian menyatakan bahwa agroindustri gula semut di tingkat rumah tangga layak untuk dikembangkan. Hasil penelitian (Purwiyati, 2015) dengan analisis DEA menyatakan ada $20 \%$ unit usaha di Kabupaten Kulon Progo yang telah efisien dan 23,33\% unit usaha di Kabupaten Purworejo. Inefesiensi usaha disebabkan karena kurang optimalnya penggunaan input. Penelitian Putri et al (2019) mengemukakan bahwa pelaku rantai pasar dalam agroindustri gula semut sangat panjang melibatkan petani kelapa, perajin gula, pengepul, Central Procesing Unit (CPU), Kelompok Usaha Bersama (KUB), Koperasi, dan Perusahaan Eksportir. Berdasarkan penelitian Putri et al (2019) terdapat 3 rantai pemasaran dalam agroindustri gula semut.

Penelitian ini akan membandingkan analisis usaha dan kelayakan usaha gula semut, central processing unit, dan kelompok usaha gula semut berbeda dengan Penelitian sebelumnya yang dilakukan oleh Maharani dan Yeni (2010); Wijayanti (2016) tentang efisiensi usaha gula semut hanya dilakukan pada satu kelompok usaha saja dan belum mengkaji setiap tier pemasaran secara komprehensif. Penelitian ini bertujuan untuk mengetahui pendapatan, biaya, dan efisiensi dari masing-masing pelaku agroindustri gula semut.

\section{METODE PENELITIAN}

Metode penelitian menggunakan metode deskriptif analisis yaitu metode penelitian untuk meneliti suatu kelompok manusia, suatu objek, suatu set kondisi, suatu pemikiran maupun suatu kelas peristiwa pada masa sekarang atau sekurang-kurangnya jangka waktu yang masih terjangkau dalam ingatan responden (Kerlinger, 2007). Penelitian ini dilakukan di Kecamatan Girimulyo dan Kecamatan Kokap sebagai sentra produksi gula semut. Metode pengumpulan data dilakukan dengan teknik Survey. Dalam metode penelitian survey, informasi diperoleh melalui wawancara secara langsung dengan responden dan observasi. Metode pengambilan sampel secara simple random sampling yang terdiri dari petani/perajin gula semut, Pengepul dan Central Processing Unit (CPU) sebanyak 60 sampel. Metode analisis data menggunakan :

\section{Analisis Biaya dan Pendapatan}

Pendapatan merupakan selisih antara penerimaan yang diterima oleh pelaku usaha gula semut dengan biaya yang dikeluarkan (biaya eksplisit) (Soekartawi, 2002).

$$
\begin{aligned}
\mathrm{NR} & =\mathrm{TR}-\mathrm{TC} \\
& =(\mathrm{Q} \times \mathrm{P})-(\mathrm{VC}+\mathrm{FC})
\end{aligned}
$$

Keterangan:

$\mathrm{NR}=$ Pendapatan $(\mathrm{Rp} / \mathrm{hari})$

$\mathrm{TR}=$ total penerimaan $(\mathrm{Rp} / \mathrm{hari})$

$\mathrm{Q}=$ Jumlah Output $(\mathrm{kg})$

$\mathrm{P}=$ Harga Output $(\mathrm{Rp} / \mathrm{kg})$

$\mathrm{TC}=$ total biaya/ total cost (eskplisit) (Rp/hari)

$\mathrm{VC}=$ total biaya variabel/ total variabel cost (Rp/hari)

$\mathrm{FC}=$ total biaya tetap/ total fix cost $(\mathrm{Rp} / \mathrm{hari})$ 
2. Analisis Kelayakan Usaha

Analisis Kelayakan usaha menggunakan RC ratio yaitu perbantingan antara penerimaan dengan total biaya.

RCRatio $=\frac{T R}{T C}$

\section{Keterangan:}

$\mathrm{TR}=$ Total Penerimaan $/$ Revenue

$\mathrm{TC}=$ Total biaya/ total cost

Dengan ketentuan

$\mathrm{R} / \mathrm{C}>1$ maka usaha agroindustri layak untuk dikembangkan karena menguntungkan

$\mathrm{R} / \mathrm{C}=1$ maka tidak untung maupun tidak rugi

$\mathrm{R} / \mathrm{C}<1$ maka usaha agroindustri mengalami kerugian

\section{HASIL DAN PEMBAHASAN}

Perajin gula semut sebagian besar mengolah nira dari kelapa milik sendiri, namun ada juga yang bekerja sebagai buruh deres dengan upah hasil nira. Agroindustri gula semut dimulai pada tahun 2008 bersamaan dengan berdirinya sentra-sentra produksi. Keterampilan pembuatan gula semut diperoleh secara turun temurun serta mendapat pendampingan petugas lapang atau sering disebut dengan ICS (Internal Control System). Hal tersebut bertujuan agar perajin mampu menghasilkan produk yang berkualitas dan dapat memperoleh keuntungan yang maksimal.

Analisis pendapatan dan kelayakan usaha merupakan salah satu alat ukur untuk menilai kinerja perusahaan. Analisis pendapatan adalah untuk mengetahui besarnya pendapatan yang diterima oleh perajin dari agroindustri gula semut per hari. Analisis pendapatan diperoleh dari total penerimaan dikurangi dengan total biaya yang meliputi biaya variabel dan biaya tetap. Biaya variabel dalam pembuatan gula semut terdiri dari biaya bahan baku, biaya bahan penolong, biaya bahan bakar, biaya kemasan dan biaya tenaga kerja. Sedangkan biaya tetap adalah biaya penyusutan. Bahan baku pembuatan gula semut adalah nira kelapa dan gula cetak. Nira kelapa biasa disebut legen merupakan cairan yang keluar dari bunga kelapa yang belum membuka. Harga bahan baku nira kelapa adalah Rp2.000,00 per liter sedangkan gula batok Rp12.500,0 per kilogram. Bahan penolong dalam pembuatan gula semut terdiri dari getah manggis dan laru (gamping). Getah manggis berfungsi sebagai pengawet alami, mencegah turunnya $\mathrm{pH}$ pada nira kelapa menambah tingkat kekentalan pada proses pemasakan nira. Biaya getah manggis sudah dikonversi senilai $\mathrm{Rp700,00}$ per liter nira. Bahan penolong yang kedua adalah laru. Laru berfungsi untuk menjaga kualitas nira kelapa yang telah disadap agar tidak masam akibat proses fermentasi. Laru dimasukkan pada bumbung atau tempat penampungan nira saat proses penyadapan. Biaya laru juga telah dikonversi senilai Rp125,00 per liter nira. Struktur biaya rata-rata disajikan pada Tabel 1.

Persentase biaya terbesar adalah biaya variabel sebesar $97,78 \%$, Sedangkan biaya tetap yaitu penyusutan alat yang merupakan biaya implisit sebesar 2,22\%. Biaya variabel eksplisit adalah biaya yang benar-benar dikeluarkan oleh perajin gula semut yaitu terdiri dari biaya bahan baku, biaya bahan penunjang dan biaya tenaga kerja luar keluarga. Biaya bahan baku terdiri dari nira dan gula batok, namun hanya sebagian kecil perajin yang mengolah dari gula batok. Penggunaan tenaga kerja luar keluarga pada tingkat perajin sangat kecil yaitu 0,134 HOK.

Tabel 1. Struktur Biaya Rata-Rata pada Perajin Gula Semut (per proses produksi)

\begin{tabular}{llr}
\hline \multicolumn{1}{c}{ Jenis Biaya } & \multicolumn{1}{c}{ Satuan } & \multicolumn{1}{c}{ Jumlah } \\
\hline Biaya Variabel & $\mathrm{Rp}$ & $65.319,44$ \\
Biaya Variabel Eksplisit & $\mathrm{Rp}$ & $51.726,94$ \\
Nira & $\mathrm{Rp}$ & $26.286,33$ \\
Getah Manggis & $\mathrm{Rp}$ & 402,03 \\
Laru & $\mathrm{Rp}$ & 50,00 \\
Kayu Bakar & $\mathrm{Rp}$ & $4.721,83$ \\
Gula Batok & $\mathrm{Rp}$ & $19.700,00$ \\
Kemasan & $\mathrm{Rp}$ & 300,08 \\
TKLK & $\mathrm{Rp}$ & 266,67 \\
Biaya Variabel Implisit & $\mathrm{Rp}$ & $13.592,50$ \\
TKDK & $\mathrm{HOK}$ & 2,17 \\
Upah & $\mathrm{Rp} / \mathrm{HOK}$ & $13.592,50$ \\
Biaya Tetap & $\mathrm{Rp}$ & $1.680,00$ \\
\hline Total Biaya & $\mathrm{Rp}$ & $66.999,44$ \\
\hline
\end{tabular}

Sumber : Data Primer diolah, 2019

Produksi rata-rata perajin adalah sebesar 5,86 kilogram gula semut per hari. Harga jual pada tingkat perajin rata-rata $\mathrm{Rp} 16.288,40$ per kilogram. Harga tersebut fluktuatif tergantung permintaan dan penawaran. Pendapatan 
Putri, D. D. : Studi Komparatif Pendapatan, Biaya dan Kelayakan ...

agroindustri gula semut pada tingkat perajin adalah $\mathrm{RP} 43.723,06$. $\mathrm{R} / \mathrm{C}$ ratio sama dengan 1,42 yang berarti bahwa agroindustri gula semut layak untuk dikembangkan. Namun nilai tersebut masih lebih rendah dibandingkan dengan penelitian Hadwa et al (2017) di Kabupaten Ciamis dengan $\mathrm{RC}$ ratio 1,43 namun pendapatannya lebih rendah yaitu sebesar Rp18.094,00 per proses produksi dibandingkan dengan pendapatan perajin pada penelitian ini sebesar Rp43.723,06.

Tabel 2. Penerimaan, Pendapatan, Keuntungan dan R/C Ratio pada Tingkat Perajin Gula Semut

\begin{tabular}{llr}
\hline Uraian & Satuan & \multicolumn{1}{c}{ Rata-Rata } \\
\hline Penerimaan & $\mathrm{Rp}$ & $\mathbf{9 5 . 4 5 0 , 0 0}$ \\
Produksi Gula Semut & $\mathrm{Kg}$ & 5,86 \\
Harga Gula Semut & $\mathrm{Rp} / \mathrm{Kg}$ & $16.288,40$ \\
Biaya Variabel & $\mathrm{Rp}$ & $65.319,44$ \\
Biaya Variabel Eksplisit & $\mathrm{Rp}$ & $51.726,94$ \\
Biaya Variabel Implisit & $\mathrm{Rp}$ & $13.592,50$ \\
Biaya Tetap & $\mathrm{Rp}$ & $1.680,00$ \\
Biaya Tetap Implisit & $\mathrm{Rp}$ & $1.680,00$ \\
Total Biaya & $\mathrm{Rp}$ & $\mathbf{6 6 . 9 9 9 , 4 4}$ \\
\hline Pendapatan & $\mathrm{Rp}$ & $43.723,06$ \\
Keuntungan & $\mathrm{Rp}$ & $28.450,56$ \\
R/C ratio & & $\mathbf{1 , 4 2}$ \\
\hline S
\end{tabular}

Sumber : Data Primer diolah, 2019

\section{Analisis Pendapatan dan Kelayakan Pedagang Pengepul Gula Semut}

Peran pengepul pada agroindustri gula semut di Kabupaten Kulon Progo ada bermacam-macam antara lain : (1) membeli gula dari perajin gula semut kemudian langsung dijual lagi ke central processing unit (CPU); (2) membeli gula batok dari perajin dan mengolahnya kembali menjadi gula semut; (3) mengolah nira menjadi gula semut dan menjualnya kepada CPU. Pengepul berperan sebagai pedagang perantara dan pengolah gula semut yang menghubungkan antara perajin binaan kelompok usaha dengan CPU. Sebagian besar pengepul menanggung biaya transportasi dan biaya kemasan. Biaya yang dikeluarkan pengepul terdiri dari biaya variabel dan biaya tetap. Biaya variabel yang dikeluarkan oleh pengepul bergantung pada jenis kegiatannya. Rerata struktur biaya terdapat pada Tabel 3.
Tabel 3. Struktur Biaya Rata-Rata pada Pedagang Pengepul Gula Semut

\begin{tabular}{llr}
\hline \multicolumn{1}{c}{ Jenis Biaya } & Satuan & \multicolumn{1}{c}{ Rerata } \\
\hline Biaya Variabel & $\mathrm{Rp}$ & $\mathbf{8 7 2 . 3 3 9 , 5 2}$ \\
Biaya Variabel Eksplisit & $\mathrm{Rp}$ & $840.839,52$ \\
Nira & $\mathrm{Rp}$ & $293.888,89$ \\
Getah Manggis & $\mathrm{Rp}$ & 339,11 \\
Laru & $\mathrm{Rp}$ & 60,56 \\
Gula Batok & $\mathrm{Rp}$ & $95.807,41$ \\
Gula Semut & $\mathrm{Rp}$ & $439.404,40$ \\
Kayu bakar & $\mathrm{Rp}$ & $6.754,07$ \\
Kemasan & $\mathrm{Rp}$ & $3.242,22$ \\
TKLK & $\mathrm{Rp}$ & $1.342,86$ \\
Biaya Variabel Implisit & $\mathrm{Rp}$ & $31.500,00$ \\
TKDK & $\mathrm{HOK}$ & 0,63 \\
& $\mathrm{Rp}$ & $31.500,00$ \\
Biaya Tetap & & $\mathbf{2 . 5 5 9 , 0 3}$ \\
Biaya Tetap Eksplisit & $\mathrm{Rp}$ & \\
Transportasi & $\mathrm{Rp}$ & $1.107,41$ \\
Biaya Tetap Implisit & $\mathrm{Rp}$ & \\
Penyusutan Alat & $\mathrm{Rp}$ & $1.451,62$ \\
\hline Total Biaya & $\mathrm{Rp}$ & $\mathbf{8 7 4 . 8 9 8 , 5 5}$ \\
\hline Sumber : Data Primer diolah, 2019 &
\end{tabular}

Biaya variabel yang dikeluarkan oleh pengepul antara lain biaya bahan baku, biaya bahan penolong dan biaya tenaga kerja; sebesar 99,57\% biaya yang dikeluarkan adalah biaya variabel dan $0,43 \%$ berupa biaya tetap. Biaya tetap terdiri dari biaya transportasi yaitu sebesar Rp1.107,41 per hari. Rata-rata produksi pada agroindustri gula semut pada tingkat pengepul adalah 880,04 kilogram dengan harga jual rata-rata Rp17.444,44. pengepul berfungsi sebagai pengumpul gula dari perajin. Sebagian besar biaya transportasi dan kemasan ditanggung oleh pengepul dan CPU. Biaya yang dikeluarkan oleh pengepul terdiri dari biaya variabel dan biaya tetap. Biaya variabel meliputi biaya bahan baku, biaya bahan penolong, biaya tenaga kerja, biaya kayu bakar, biaya kemasan. Sedangkan biaya tetap meliputi penyusutan alat dan biaya transportasi. Penerimaan rata-rata pengepul Rp1.093.068,61 per hari dengan total biaya Rp874.898,55 sehingga diperoleh pendapatan Rp1.058.416,33. Pendapatan tersebut lebih tinggi dibandingkan dengan pendapatan di tingkat perajin. $\mathrm{R} / \mathrm{C}$ ratio diperoleh 1,25 pada tingkat pedagang pengepul. Nilai R/C ratio tersebut lebih rendah dibandingkan dengan perajin gula semut. Hal ini disebabkan biaya yang dikeluarkan 
Putri, D. D. : Studi Komparatif Pendapatan, Biaya dan Kelayakan ...

pengepul jauh lebih besar karena pengepul harus menanggung biaya pemasaran. Penerimaan, pendapatan, keuntungan dan $\mathrm{R} / \mathrm{C}$ ratio di tingkat pengepul disajikan di Tabel 4.

Tabel 4. Penerimaan, Pendapatan, Keuntungan dan R/C Ratio pada Tingkat Pengepul Gula Semut

\begin{tabular}{llr}
\hline Uraian & Satuan & \multicolumn{1}{l}{ Rerata } \\
\hline Penerimaan & $\mathrm{Rp}$ & $\mathbf{1 . 0 9 3 . 0 6 8 , 6 1}$ \\
Produksi Gula Semut & $\mathrm{Kg}$ & 62,66 \\
Harga Gula Semut & $\mathrm{Rp} / \mathrm{Kg}$ & $17.444,44$ \\
Biaya Variabel : & $\mathrm{Rp}$ & \\
Biaya Variabel Eksplisit & $\mathrm{Rp}$ & $840.839,52$ \\
Biaya Variabel Implisit & $\mathrm{Rp}$ & $31.500,00$ \\
Biaya Tetap : & & \\
Biaya Tetap Eksplisit & $\mathrm{Rp}$ & \\
$\quad$ Transportasi & $\mathrm{Rp}$ & $1.107,41$ \\
Biaya Tetap Implisit & $\mathrm{Rp}$ & \\
$\quad$ Penyusutan Alat & $\mathrm{Rp}$ & $1.451,62$ \\
Total Biaya & $\mathrm{Rp}$ & $\mathbf{8 7 4 . 8 9 8 , 5 5}$ \\
\hline Pendapatan & $\mathrm{Rp}$ & $251.121,68$ \\
Keuntungan & $\mathrm{Rp}$ & $218.170,06$ \\
\hline R/C ratio & & $\mathbf{1 , 2 5}$ \\
\hline Sumber : Data Prim
\end{tabular}

Sumber : Data Primer diolah, 2018

\section{Analisis Pendapatan dan Kelayakan CPU Gula Semut}

Central Processing Unit (CPU) berada di bawah sentra produksi. Ada $10 \mathrm{CPU}$ yang masih aktif dan bertempat di Kecamatan Kokap, Girimulyo dan Nanggulan. CPU berfungsi sebagai pengolah gula semut, grading dan standarisasi produk. CPU sudah melakukan proses pengovenan dan penyaringan sesuai standar permintaan. Setiap CPU mendapat kuota gula semut dari sentra produksi sesuai dengan kapasitas produksi masing-masing CPU. Penerimaan, biaya dan pendapatan pada tingkat CPU gula semut terdapat pada Tabel 5 .

Biaya variabel yang dikeluarkan oleh CPU meliputi biaya bahan baku, bahan penunjang, biaya operasional, dan biaya tenaga kerja. Biaya bahan baku meliputi biaya untuk bahan baku gula batok dengan rata-rata sebesar Rp1.887.500,00, pembelian gula semut dengan rata-rata Rp3.775.000,00. Biaya operasional pada tingkat CPU meliputi biaya listrik, oven dan air yang dikeluarkan selama proses pengeringan menggunakan oven.
Tabel 5. Struktur Biaya Rata-Rata pada CPU Gula Semut

\begin{tabular}{llr}
\hline \multicolumn{1}{c}{ Jenis Biaya } & Satuan & \multicolumn{1}{c}{ Rerata } \\
\hline Biaya Variabel & $\mathrm{Rp}$ & $\mathbf{6 . 0 3 0 . 5 3 1 , 2 4}$ \\
Biaya Variabel Eksplisit & $\mathrm{Rp}$ & $5.987 .031,24$ \\
gula batok & $\mathrm{Rp}$ & $1.887 .500,00$ \\
gula semut & $\mathrm{Rp}$ & $3.775 .000,00$ \\
kayu bakar & $\mathrm{Rp}$ & $30.943,6$ \\
kemasan & $\mathrm{Rp}$ & $24.620,00$ \\
oven & $\mathrm{Rp}$ & $29.003,60$ \\
listrik & $\mathrm{Rp}$ & $14.501,80$ \\
air & $\mathrm{Rp}$ & $14.501,80$ \\
penyusutan gula & $\mathrm{Rp}$ & $98.612,24$ \\
Upah Tenaga kerja LK & $\mathrm{Rp}$ & $126.850,00$ \\
Biaya Variabel Implisit & $\mathrm{Rp}$ & $43.500,00$ \\
Jumlah Tenaga Kerja DK & $\mathrm{HOK}$ & 0,87 \\
Upah TKDK & $\mathrm{Rp}$ & $43.500,00$ \\
Biaya Tetap & & $130.998,50$ \\
Biaya Tetap Eksplisit & $\mathrm{Rp}$ & $130.998,50$ \\
Penyusutan & $\mathrm{Rp}$ & $16.511,80$ \\
Sewa tempat produksi & $\mathrm{Rp}$ & $16.911,80$ \\
transportasi & $\mathrm{Rp}$ & $89.119,00$ \\
administrasi & $\mathrm{Rp}$ & $8.455,90$ \\
\hline Total Biaya & $\mathrm{Rp}$ & $\mathbf{6 . 1 6 1 . 5 1 9 , 7 4}$ \\
\hline Sumber : Data Primer & $\mathrm{R}$ &
\end{tabular}

Sumber : Data Primer diolah, 2019

Persentase biaya variabel yang dikeluarkan oleh CPU $97,88 \%$ dan $2,12 \%$ berupa biaya tetap. Pada tingkat CPU biaya tetap berupa penyusutan alat, sewa tempat produksi dan transportasi merupakan biaya tetap eksplisit yang sudah dikeluarkan oleh CPU. Penerimaan, pendapatan, keuntungan dan $\mathrm{RC}$ ratio pada tingkat CPU terdapat pada Tabel 6.

Tabel 6. Penerimaan, Pendapatan, Keuntungan dan RC Ratio pada Tingkat Pengepul Gula Semut

\begin{tabular}{llr}
\hline \multicolumn{1}{c}{ Uraian } & \multicolumn{1}{c}{ Satuan } & \multicolumn{1}{c}{ Rata-Rata } \\
\hline Penerimaan & $\mathrm{Rp}$ & $\mathbf{6 . 9 3 3 . 9 2 0 , 0 0}$ \\
Produksi Gula Semut & $\mathrm{Kg}$ & 338,24 \\
Harga Gula Semut & $\mathrm{Rp} / \mathrm{Kg}$ & $20.500,00$ \\
Total Biaya Variabel & $\mathrm{Rp}$ & $6.030 .531,24$ \\
Biaya Variabel Eksplisit & $\mathrm{Rp}$ & $5.987 .031,24$ \\
Biaya Variabel Implisit & $\mathrm{Rp}$ & $43.500,00$ \\
Total Biaya Tetap & & $130.998,50$ \\
Biaya Tetap Eksplisit & $\mathrm{Rp}$ & $130.998,50$ \\
Total Biaya & $\mathrm{Rp}$ & $\mathbf{6 . 1 6 1 . 5 1 9 , 7 4}$ \\
\hline Pendapatan & $\mathrm{Rp}$ & $815.900,26$ \\
Keuntungan & $\mathrm{Rp}$ & $772.400,26$ \\
\hline RC ratio & & $\mathbf{1 , 1 2}$ \\
\hline Sumber: Data Primer diolah, 2019 &
\end{tabular}

Sumber : Data Primer diolah, 2019 
Produksi rata-rata CPU adalah 338,24 kilogram gula semut dengan harga di tingkat CPU rata-rata Rp20.500,00. Harga jual sangat fluktuatif sesuai dengan permintaaan dan penawaran gula semut. Biaya variabel yang dikeluarkan oleh CPU terdiri dari biaya bahan baku, biaya bahan penolong, biaya tenaga kerja, biaya listrik, oven dan gas,dan biaya kemasan. Sedangkan biaya tetap yang dikeluarkan terdiri dari biaya penyusutan alat, biaya sewa tempat produksi, biaya transportasi dan biaya administrasi. Total biaya yang dikeluarkan CPU Rp6.161.519,74, maka pendapatan yang diperoleh CPU adalah Rp815.900,26. Sedangkan keuntungan diperoleh dari penerimaan dikurangi dengan biaya total eksplisit maupun implisit diperoleh sebesar Rp772.400,26.

Kelayakan usaha diukur dari RC ratio diperoleh RC ratio pada tingkat CPU sebesar 1,12. Hal tersebut menunjukkan bahwa agroindustri layak untuk dikembangkan. Perbandingan nilai RC ratio pada tingkat perajin, pengepul dan CPU terdapat pada Gambar 1.

Pendapatan tertinggi adalah CPU gula semut, diikuti dengan pedagang pengepul dan perajin gula semut. Hal ini dikarenakan Kapasitas produksi CPU jauh lebih tinggi dibandingkan pengepul dan perajin. Produksi pada skala industri rumah tangga masih sangat rendah, hal ini dikarenakan rata-rata kepemilikan pohon hanya 15 batang per rumah tangga produksi dan rata-rata hanya menghasilkan bahan baku gula semut 13,14 liter nira per hari. Perajin dapat meningkatkan produksinya dengan cara mengolah gula batok menjadi gula semut. Keterbatasan modal juga menjadi kendala bagi perajin untuk mengembangkan usahanya. Perajin rata-rata menggunakan modal sendiri dan pinjaman dari pengepul. Namun adanya agroindustri gula semut mampu meningkatkan harga jual dari gula yang sebelumnya harga jual gula cetak hanya sebesar Rp12.500,00 setelah diolah menjadi gula semut harga jualnya Rp16.287,50.

Perbandingan $\mathrm{RC}$ ratio setiap tingkat rantai pasok terdapat pada Gambar 1. nilai tertinggi $\mathrm{RC}$ ratio terdapat pada perajin gula semut, yang kedua adalah agroindustri tingkat CPU dan yang ketiga adalah di tingkat pengepul. Perbandingan ini menunjukkan rasio besarnya penerimaan dengan biaya yang dikeluarkan pada agroindustri gula semut di masing-masing rantai pasok.

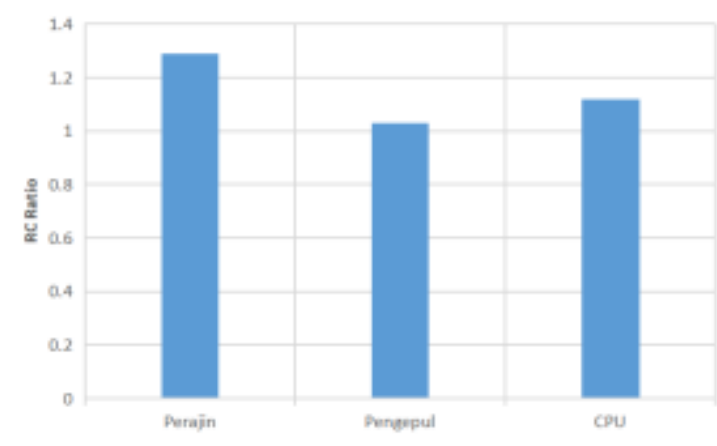

Gambar 1. Perbandingan RC ratio Agroindustri Gula Semut

Dari semua rantai agroindustri gula semut layak untuk dikembangkan melalui berbagai inovasi teknologi dan manajemen.

\section{KESIMPULAN}

Hasil penelitian menunjukkan bahwa keuntungan tertinggi ada pada Central Processing unit (CPU), kemudian pedagang pengepul, dan terakhir adalah di tingkat perajin gula semut skala rumah tangga. Hal tersebut disebabkan skala usaha yang berbeda, keterbatasan modal dan bahan baku menjadi hambatan perajin dalam mengembangkan usahanya. Sedangkan dilihat dari kelayakan RC ratio semua $\mathrm{RC}$ ratio $>1$ artinya pada semua usaha pada rantai pemasaran layak untuk dijalankan. RC ratio pada CPU lebih kecil dibandingkan pada perajin dan pedagang, hal ini disebabkan CPU dan pedagang pengepul menanggung lebih banyak biaya variabel produksi dan pemasaran. Studi komparatif ini menunjukkan rasio besarnya penerimaan dengan biaya yang dikeluarkan pada agroindustri gula semut di masing-masing rantai pasok. Dari semua rantai agroindustri gula semut layak untuk dikembangkan melalui berbagai inovasi teknologi dan manajemen.

\section{DAFTAR PUSTAKA}

Antriyandarti, E. 2019. Peran Koperasi dalam Pemasaran Produk Kelapa di Era Industri 4.0. Prosiding Seminar Nasional Program Studi Agribisnis Fakultas Pertanian Universitas Jember, 428-432. 
Putri, D. D. : Studi Komparatif Pendapatan, Biaya dan Kelayakan ...

Hadwa, I., Soetoro, Noormansyah, Z. 2017. Analisis Usaha dan Nilai Tambah Agroindustri Gula Semut Studi Kasus di Desa Sidamulih, Kecamatan Pamarican Kabupaten Ciamis. Agroinfo Galuh, 3(2), 220-225.

Iryanti, D., Affandi, I., Nugraha, A. 2011. Analisis Kinerja, Nilai Tambah, dan Strategi Pengembangan Agroindustri Kecil Kelanting (Skripsi). Lampung: Fakultas Pertanian, Universitas Lampung.

Kerlinger. 2007. Metode Penelitian Behavioral. Yogyakarta: Gadjah Mada University Press.

Maharani, E dan Yeni, K. 2010. Strategi Pemasaran Gula Semut di Kabupaten Rokan Hulu, Propinsi Riau. Jurnal IJAE, 2(1), 120-131.

Prihtanto, F. N. P., Irham, Suryantini, A. 2015. Analisis Industri Rumah Tangga Gula Semut untuk Ekspor di Kabupaten Kulon Progo dan Purworejo. Agro Ekonomi, 26(1), 22-33. https://doi.org/10.22146/ jae. 18033

Purwiyati, I., Irham, Hartono, S. 2015. Analisis Efesiensi Industri Pengolahan Gula Semut dengan Metode Data Envelopment
Analysis di Kabupaten Kulon Progo dan Kabupaten Purworejo (Skripsi). Yogyakarta: Universitas Gadjah Mada.

Putri, M. N. A., Adi, R. A., Khomah, I. 2019. Analisis Usaha dan Pemasaran Gula Semut di Desa Hargotirto, Kecamatan Kokap, Kabupaten Kulon Progo. SEPA(Jurnal Sosial Ekonomi Pertanian Dan Agribisnis), 16(1), 74-78. https:// doi.org/10.20961/sepa.v16i1.22470.

Soekartawi. 2002. Analisis Usahatani. Jakarta: Universitas Indonesia Press.

Wibowo, D., Maharani, E., Eliza. 2020. Analisis Keuntungan Agroindustri Gula Kelapa Di Kecamatan Tempuling Kabupaten Indragiri Hilir. SEPA (Jurnal Sosial Ekonomi Pertanian Dan Agribisnis), 16(2), 172-176. https://doi. org/10.20961/sepa.v16i2.35336.

Wijayanti, D. E., Hartono, S., Darwanto, H. D. 2016. Efisiensi Agroindustri Gula Semut di Kecamatan Kokap, Kabupaten Kulon Progo (Tesis). Yogyakarta: Universitas Gadjah Mada. 